\title{
ANÁLISE DINÂMICA NÃO LINEAR DE EDIFÍCIOS MISTOS (AÇO-CONCRETO)
}

\author{
R. R. Barboza ${ }^{1}$, I. A. R. da Silva ${ }^{1}$, J. G. S. da Silva ${ }^{2}$, F. J. da C. P. Soeiro ${ }^{3}$, L. R. O. de Lima ${ }^{2}$ \\ ${ }^{1}$ Programa de Pós-graduação em Engenharia Civil, PGECIV, Universidade do Estado do Rio \\ de Janeiro, UERJ (rafael_engciv@yahoo.com.br)
}

${ }^{2}$ Departmento de Estruturas e Fundações, Universidade do Estado do Rio de Janeiro, UERJ

${ }^{3}$ Departmento de Engenharia Mecânica, Universidade do Estado do Rio de Janeiro, UERJ

Resumo. Com base em um cenário econômico favorável conjugado aos avanços tecnológicos das ciências dos materiais e processos de construção, nas últimas três décadas, as cidades brasileiras têm apresentado um crescimento substancial, no que diz respeito à construção de edificios residenciais e comerciais de múltiplos andares. Atualmente, estes edifícios apresentam níveis de esbeltez elevados e têm sido construídos com estruturas cada vez mais ousadas e que englobam a experiência e o conhecimento dos engenheiros de estruturas. Como o principal objetivo dos projetistas está associado à concepção de estruturas mais leves, o projeto estrutural requer um conhecimento teórico substancial a fim de tornar compativeis os requisitos arquitetônicos com as condições necessárias para a estabilidade. Assim sendo, o objetivo deste trabalho é o de investigar o comportamento estrutural de um edifício misto (açoconcreto) de 20 pavimentos. Para tal, o estudo apresenta os resultados de análises estáticas e dinâmicas lineares e não lineares para ações de serviço. O comportamento estrutural do edificio, quando submetido às ações dinâmicas induzidas pelo vento, também foi investigado. Os resultados revelam que edifícios esbeltos merecem atenção especial, no que diz respeito à concepção do projeto estrutural, sendo que seu comportamento deve ser verificado através de metodologias que incluam análises do tipo estática e dinâmica (lineares e não lineares).

Palavras-chave: Edificios esbeltos, Análise dinâmica não linear, Comportamento estrutural.

\section{INTRODUCÃO}

Atualmente, a construção civil nas grandes cidades do Brasil tem apresentado edifícios residenciais e comerciais cada vez mais altos e esbeltos, fruto de uma condição econômica favorável e do avanço tecnológico dos materiais e processos construtivos. Esta tendência arquitetônica tem conduzido o projeto dessas edificações a soluções compostas por sistemas estruturais flexíveis, resultando em edifícios esbeltos e com valores de frequências naturais muito baixas e, consequentemente, mais suscetíveis a problemas de vibrações excessivas, abertura de fissuras indesejáveis e, em casos mais graves, fadiga e colapso da estrutura [1-3]. 
Considerando-se os níveis de esbeltez apresentados mais recentemente, estes edifícios necessitam ter o seu comportamento dinâmico linear e não linear investigado, de forma que sejam garantidos o conforto e a segurança dos usuários. Por outro lado, a ação do vento passa a ter uma importância bastante relevante na medida em que as edificações deixam de ser mais baixas e pesadas, por tanto rígidas, e passam a ser muito esbeltas [1-3].

De acordo com a norma brasileira de vento NBR 6123 [4], o vento é produzido por diferenças de pressão e de deslocamento de massas de ar na atmosfera. As diferenças de pressão podem causar movimentos que variam de brisas a intensos tornados. A ação do vento é composta por uma parcela constante (velocidade média) e por uma parcela flutuante (rajadas), cuja velocidade varia em torno da velocidade média. Por sua vez, as rajadas de vento ocorrem numa sequência aleatória de frequências e intensidades. Pequenos turbilhões, cuja ação é localizada e desordenada, dão origem a rajadas mais violentas, que podem gerar forças de dois tipos: forças com componentes de altas frequências e baixa intensidade; e forças contendo componentes de baixas frequências e alta intensidade [1-3].

Deve-se ressaltar que estruturas de edifícios podem vir a ter frequências naturais muito baixas. Desta maneira, ventos com rajadas compostas por harmônicos com altas frequências terão pouca influência sobre a resposta dinâmica da edificação. De outra forma, ventos com rajadas formadas por harmônicos compostos por baixas frequências podem estar em fase com toda a estrutura, caracterizando um estado ressonante. Nesta situação, a resposta dinâmica do edifício torna-se muito amplificada, por exemplo, com valores de deslocamentos excessivos, podendo vir a causar, em casos extremos, inclusive, a ruína do sistema estrutural [1-3].

Na prática corrente de projeto, a ação do vento sobre um edifício é representada por meio de um carregamento estático equivalente. Contudo, tal hipótese é, no mínimo, questionável, pois desconsidera o caráter dinâmico da excitação. Como a ação do vento possui um caráter aleatório ou randômico, uma modelagem mais realista deve considerar um tratamento probabilístico adequado para definição da excitação dinâmica [1-2].

A norma NBR 6123 [4] baseia-se no modelo espectral proposto por Davenport apud Blessmann [5], para descrever a ação do vento. Por outro lado, na literatura técnica são encontrados diversos estudos que descrevem modelos matemáticos que representam as rajadas de vento, tal como o Método do Vento Sintético proposto por Franco (apud Obata [6]), por meio da geração de séries históricas de carregamento, o qual tem sido adotado em inúmeros trabalhos de pesquisa [6-10]. Pode-se empregar, ainda, a modelagem via simulação de Monte Carlo para representar a ação do vento em estruturas [6-10].

Assim sendo, o objetivo deste trabalho de pesquisa é o de investigar o comportamento dinâmico de edifícios esbeltos em aço e mistos (aço-concreto) submetidos à ação do vento. Para tal, este estudo aborda o desenvolvimento de modelos numéricos tridimensionais, via método dos elementos finitos, com base na utilização do programa ANSYS [11]. A estratégia de modelagem leva em conta a influência da rigidez dos painéis de alvenarias, para analisar resposta dinâmica de um edifício de vinte pavimentos [11], composto por vigas e colunas de aço e lajes de concreto armado, formando um sistema estrutural misto com interação total. Nesta investigação, a modelagem das rajadas de vento atuantes sobre o modelo estrutural é feita com base em uma modelagem simplificada, por meio do emprego de funções harmônicas senoidais. 


\section{AÇÃO DO VENTO EM ESTRUTURAS}

A norma NBR 6123 [4] estabelece que nas estruturas onde a ação do vento possa vir a produzir efeitos estáticos e dinâmicos significativos, deve-se realizar um estudo para que sejam avaliados tais efeitos em estruturas com nós deslocáveis cuja altura seja maior que quatro vezes a largura ou numa determinada direção onde o número de filas de pilares seja inferior a quatro.

No que diz respeito ao vento natural, o módulo e a orientação da velocidade instantânea do ar apresentam flutuações em torno da velocidade média, designadas por rajadas. Admite-se que a velocidade média mantém-se constante durante um intervalo de tempo de $10 \mathrm{~min}$ ou mais, produzindo nas edificações efeitos puramente estáticos, designados a seguir como resposta média. Já as flutuações da velocidade podem induzir em estruturas muito flexíveis, especialmente em edificações altas e esbeltas, oscilações importantes na direção da velocidade média, aqui designadas como resposta flutuante [4].

Nas edificações cujo período fundamental $\left(T_{1}\right)$ é igual ou inferior a $1 \mathrm{~s}$, a influência da resposta flutuante é pequena, sendo seus efeitos já considerados na determinação do intervalo de tempo adotado para o fator relacionado com a rugosidade do terreno. Entretanto, edificações cujo período fundamental é superior a $1 \mathrm{~s}$, em particular aquelas fracamente amortecidas, podem apresentar importante resposta flutuante na direção do vento médio. A resposta dinâmica total, de uma estrutura submetida às cargas de vento, é igual à superposição das respostas média e flutuante da estrutura [4].

Para a avaliação do comportamento estrutural de uma edificação submetida à ação do vento, a norma brasileira de vento NBR 6123 [4] recomenda dois modelos para calcular os picos de rajadas: modelo contínuo simplificado e o modelo discreto. Este trabalho de pesquisa utiliza o modelo contínuo simplificado para se determinar a ação do vento (picos de rajada), ao longo da altura da edificação.

\subsection{Modelo contínuo simplificado de acordo com a NBR 6123 [4]}

Segundo a norma NBR 6123 [4], o modelo contínuo simplificado pode ser adotado para edifícios cuja seção seja constante e que a distribuição de massa da estrutura seja aproximadamente uniforme. Estas edificações também devem ser apoiadas exclusivamente na base e tenham altura inferior a $150 \mathrm{~m}$. Apenas o modo fundamental contribui para a resposta dinâmica da estrutura, o que conduz, em geral, a erros inferiores a $10 \%$ no que diz respeito à resposta dinâmica do modelo investigado.

A NBR 6123 [4] estabelece para cada tipo de estrutura parâmetros para determinação dos efeitos dinâmicos: período fundamental, $\mathrm{T}_{1}$, razão de amortecimento crítico, $\zeta$, e o parâmetro $\gamma$. A estrutura investigada neste trabalho diz respeito a um edifício misto (açoconcreto), com estrutura de aço soldada.

O período fundamental teórico do edifício é dado pela Equação (1), onde h corresponde à altura da edificação em metros.

$$
T_{1}=0,29 \sqrt{h}-0,4
$$


A variação da pressão dinâmica em função da altura é dada pela Equação (2), onde o primeiro termo entre colchetes corresponde à resposta média e o segundo representa a amplitude máxima da resposta flutuante.

$$
q(z)=\bar{q}_{0} b^{2}\left[\left(\frac{z}{z_{\text {ref }}}\right)^{2 p}+\left(\frac{h}{z_{\text {ref }}}\right)^{p}\left(\frac{z}{h}\right)^{\gamma} \frac{(1+2 \gamma)}{(1+\gamma+p)} \xi\right]
$$

Na Equação (2), o valor do termo $z_{r e f}$ é igual a $10 \mathrm{~m}$, já o expoente $p$ e o coeficiente $b$ dependem da categoria de rugosidade do terreno. O coeficiente de amplificação dinâmica, $\xi$, é apresentado no documento da NBR 6123 [4] na forma de gráficos como sendo função das dimensões da edificação, da razão de amortecimento crítico, $\zeta$, e da frequência, $f$, a qual é obtida através da relação adimensional entre a velocidade de projeto e o produto entre a frequência e a variável $\mathrm{L}(\mathrm{L}=1800): \bar{V}_{P} / f L$.

Na sequência, a pressão dinâmica do vento $\bar{q}_{0}$, expressa em N/m² é calculada com base no emprego da Equação (3).

$$
\bar{q}_{0}=0,613 \bar{V}_{P}
$$

A velocidade de projeto, $\bar{V}_{P}$, que corresponde à velocidade média em 10 minutos a 10 m de altura do solo, é expressa pela Equação (4):

$$
\bar{V}_{P}=0,69 V_{0} S_{1} S_{3}
$$

$\mathrm{Na}$ Equação (4), $V_{0}$ representa a velocidade básica do vento, que depende do local onde a estrutura foi construída, $\mathrm{S}_{1}$ corresponde ao fator topográfico e $\mathrm{S}_{3}$ relaciona-se ao fator estatístico. A força estática equivalente do vento, dada por unidade de altura da edifícação, é calculada pela Equação (5).

$$
F(z)=q(z) C_{a} L_{1}
$$

Na Equação (5), $C_{a}$ corresponde à média dos coeficientes de arrasto para ventos de alta e baixa turbulência, obtidos através dos gráficos da norma NBR 6123 [4] e $\mathrm{L}_{1}$ corresponde à largura da edificação perpendicular à ação do vento. Existem dois valores para o parâmetro $C_{a}$ para cada direção da estrutura (frontal e lateral): para os ventos de alta turbulência e para os ventos de baixa turbulência. A recomendação da norma NBR 6123 [4] é que se faça uma média entre os dois valores.

\section{MODELO ESTRUTURAL INVESTIGADO}

$\mathrm{O}$ modelo estrutural investigado neste trabalho de pesquisa associa-se a um edifício misto (aço-concreto) com 20 pavimentos, pé-direito de 3,30 m, com altura de $66 \mathrm{~m}(h=66 \mathrm{~m})$ e dimensões em planta de $30 \mathrm{~m}$ x $20 \mathrm{~m}$, conforme ilustrado na Figura 1. A Figura 2 ilustra os painéis de contraventamento metálicos do edifício [12]. 
A edificação apresenta lajes em concreto armado com espessura de $15 \mathrm{~cm}$, as vigas, colunas e diagonais são compostas por perfis laminados padrão europeu e um núcleo formado por painéis treliçados, conforme Tabela 1. O modelo estrutural investigado neste trabalho de pesquisa representa uma adaptação de um sistema estrutural proposto por Assis [12].

No que diz respeito à característica física dos materiais, o concreto possui resistência característica à compressão $\left(f_{c k}\right)$ igual a $30 \mathrm{MPa}$, módulo de elasticidade longitudinal secante $\left(E_{c s}\right)$ de $3 \times 10^{10} \mathrm{~N} / \mathrm{m}^{2}$, coeficiente de Poisson ( $v$ ) igual a 0,2 e densidade $\left(\gamma_{c}\right)$ de $25 \mathrm{kN} / \mathrm{m}^{3}$. Para o aço tem-se uma resistência característica $\left(f_{y}\right)$ de $500 \mathrm{MPa}$, módulo de elasticidade $\left(E_{s}\right)$ de $2,05 \times 10^{11} \mathrm{~N} / \mathrm{m}^{2}$, coeficiente de Poisson $(v)$ igual a 0,3 e densidade $\left(\gamma_{s}\right)$ de $78,5 \mathrm{kN} / \mathrm{m}^{3}$.

Tabela 1. Perfis laminados padrão europeu do edifício [12].

\begin{tabular}{cc}
\hline Elementos Estruturais & Perfil de Aço \\
\hline Colunas $\left(\right.$ andar $1^{\circ}$ ao $\left.10^{\circ}\right)$ & HE450B \\
Colunas $\left(\right.$ andar $11^{\circ}$ ao $\left.20^{\circ}\right)$ & HE450A \\
Vigas & IPE550V \\
Diagonais & HE260M \\
\hline
\end{tabular}

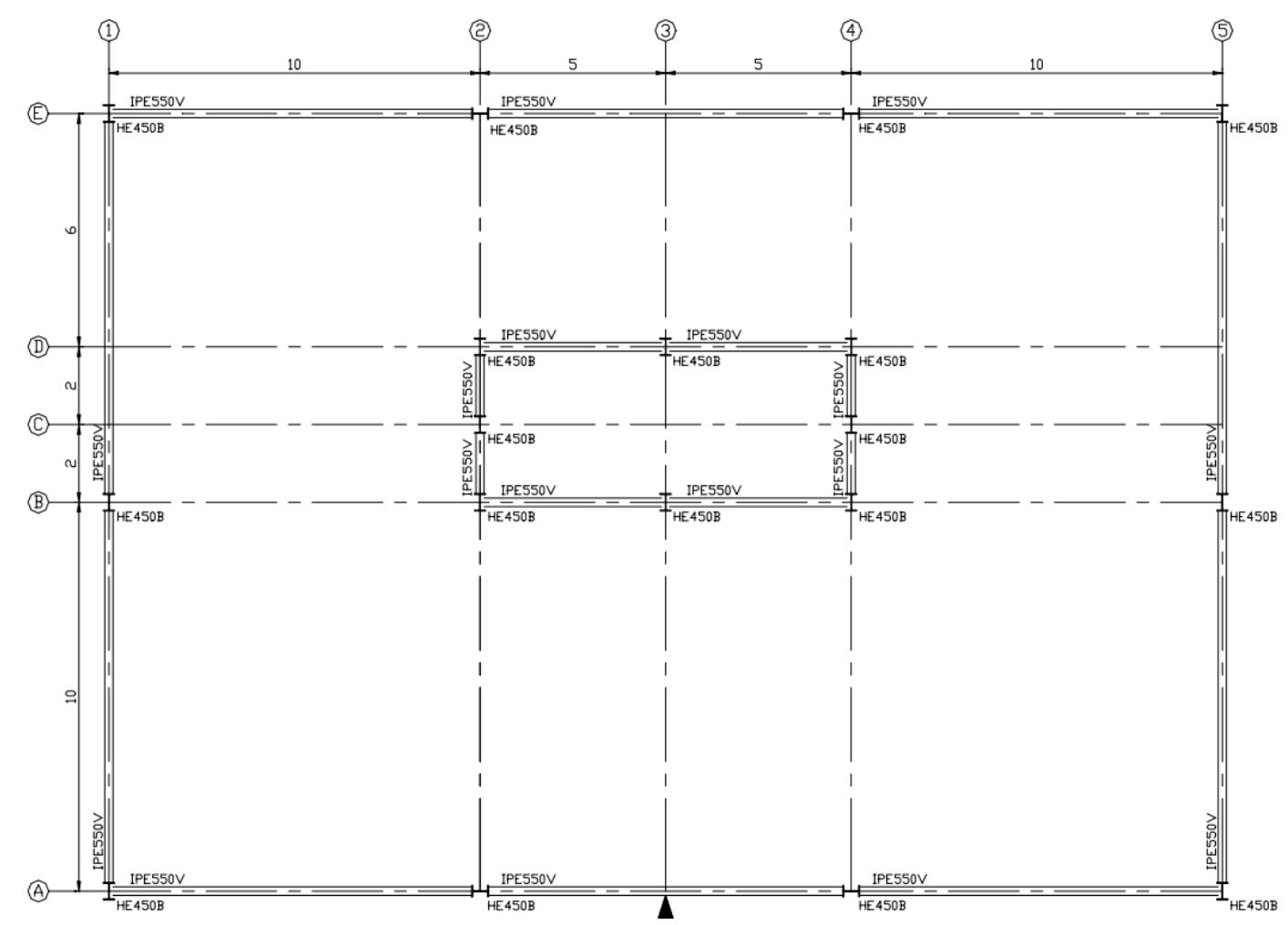

Figura 1. Planta baixa do modelo estrutural [12].

\section{MODELO NUMÉRICO}

O sistema estrutural investigado foi modelado a partir de técnicas usuais de discretização, via método dos elementos finitos, por meio da utilização do programa computacional ANSYS [11]. A análise numérica considera interação completa entre o aço e o concreto e que os materiais trabalham em regime linear-elástico. 
O modelo computacional foi desenvolvido utilizando-se elementos finitos de casca SHELL63 [11] para simular as lajes de concreto armado da edificação. As vigas e colunas de aço foram representadas por elementos finitos de viga tridimensionais BEAM44 [11], onde são considerados os efeitos de flexão e torção. O elemento finito de treliça espacial LINK8 [11] foi empregado para simular as diagonais de contraventamento.
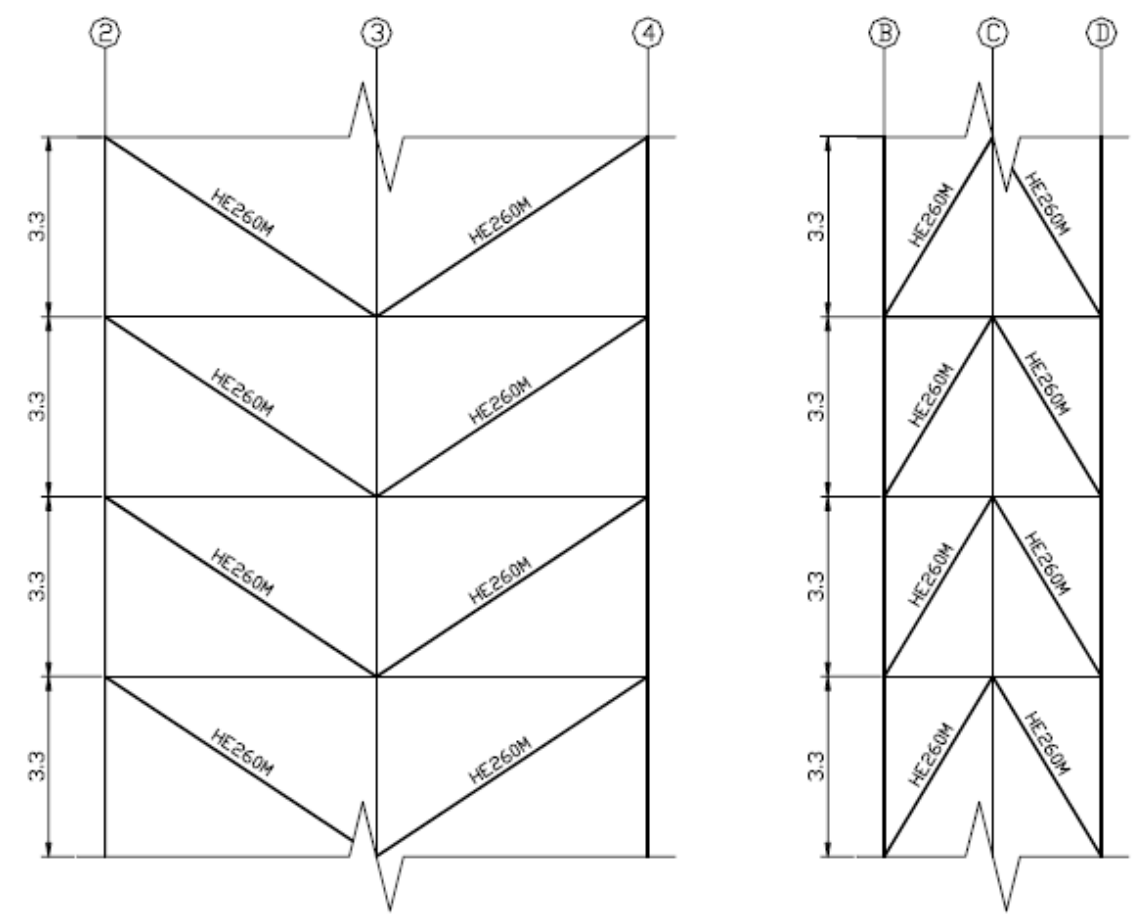

Figura 2. Painéis treliçados do edifício [12].

O presente modelo numérico possui um grau de refinamento adequado, permitindo uma boa representação do comportamento dinâmico da estrutura analisada, no que diz respeito à malha de elementos finitos, apresentando 49178 nós, 44800 elementos finitos de casca SHELL63 [11], 11600 elementos finitos de viga BEAM44 [11], 440 elementos finitos de treliça LINK8 [11] e possui 295014 graus de liberdade.

As condições de contorno foram aplicadas sobre o modelo numérico na base da edificação, de modo a restringir as deslocabilidades dos pilares, no que diz respeito aos deslocamentos translacionais (horizontais e verticais), no que tange as direções globais $X, Y$ e $Z$, simulando apoios de segundo gênero tridimensionais. As rotações na base dos pilares não são restringidas. $\mathrm{O}$ modelo em elementos finitos desenvolvido encontra-se ilustrado na Figura 3.

O elemento finito de casca SHELL63 [11] é definido por quatro nós apresentando seis graus de liberdade em cada nó: três translações e três rotações associadas às direções $x, y, \mathrm{e} z$, como ilustrado na Figura 4. O elemento finito de viga BEAM44 [11] é um elemento uniaxial composto por dois nós e cada nó possui seis graus de liberdade: translação nas direções $x, y$, e $\mathrm{z}$ e rotação nos eixos $x, y$, e z, como mostrado na Figura 5. O elemento finito de treliça LINK8 [11] é definido como um elemento de deformação uniaxial com dois nós e três graus de liberdade por cada nó, translação nas direções $x$ e $y$, conforme Figura 6. 


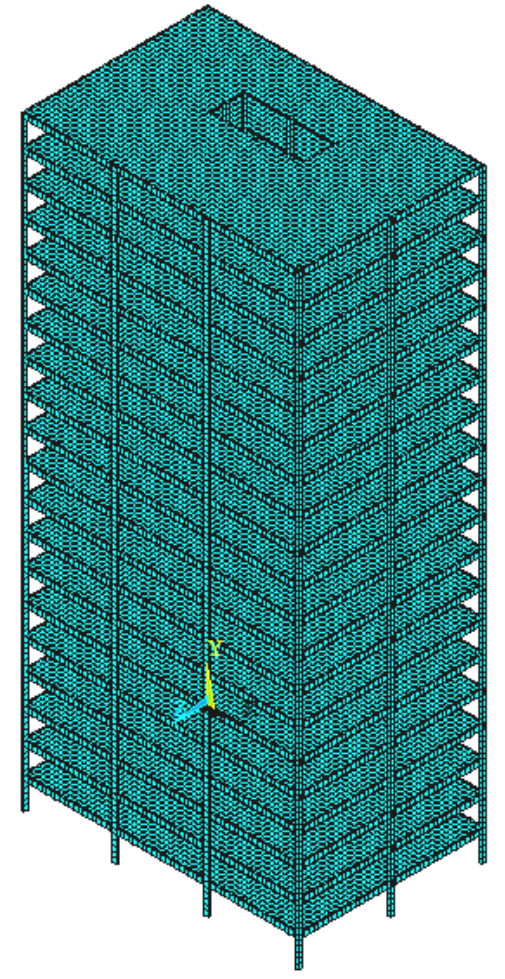

a) Perspectiva do modelo em elementos finitos.

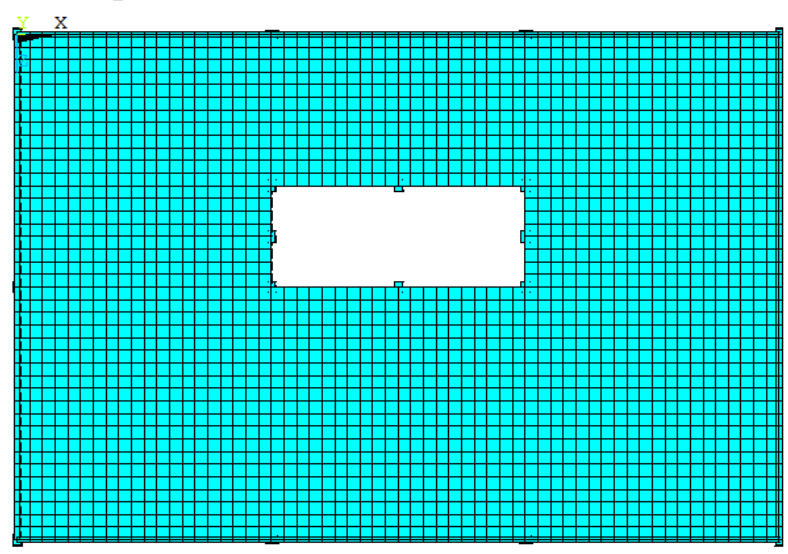

c) Vista superior do modelo numérico.

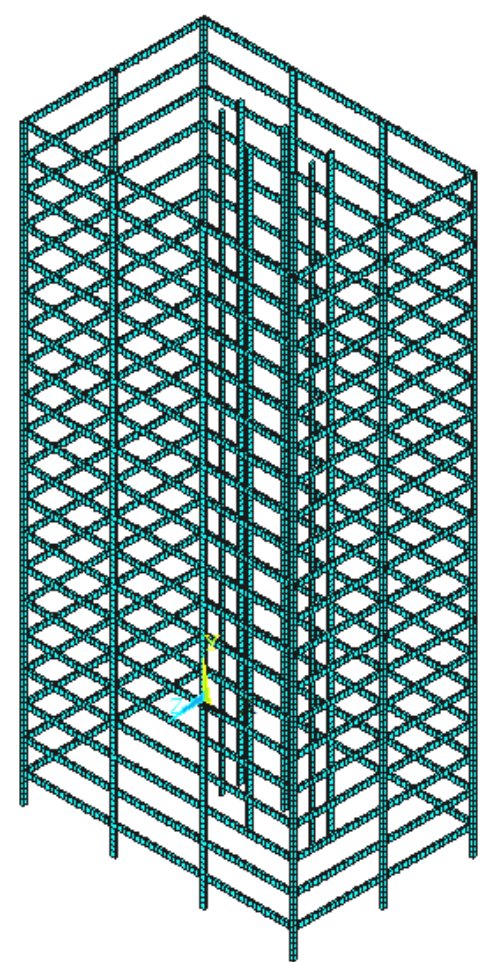

b) Perspectiva do modelo sem as lajes.
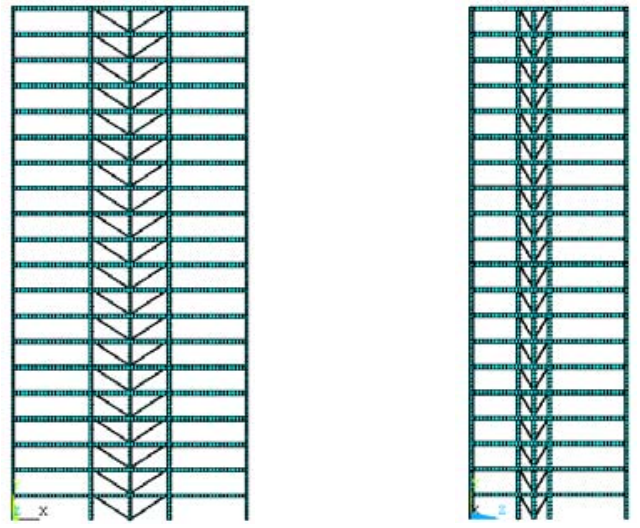

d) Vistas frontal e lateral do modelo numérico.

Figura 3. Modelo em elementos finitos do edifício [1].

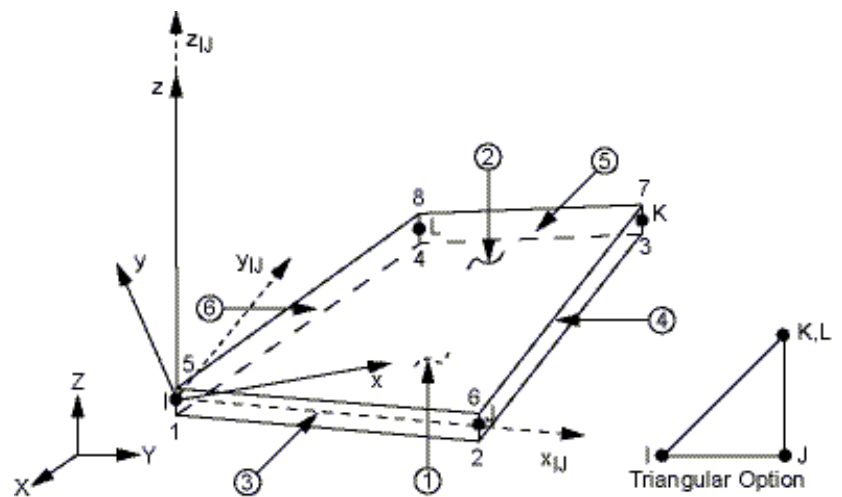

Figura 4. Elemento finito de casca SHELL63 [11]. 

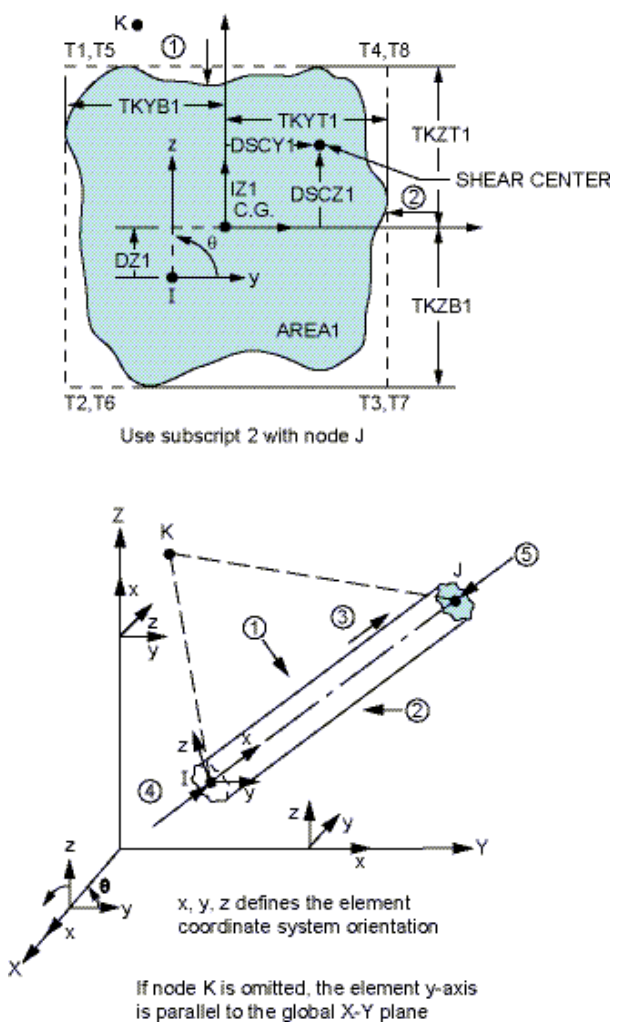

Figura 5. Elemento finito de viga tridimensional BEAM44 [11].
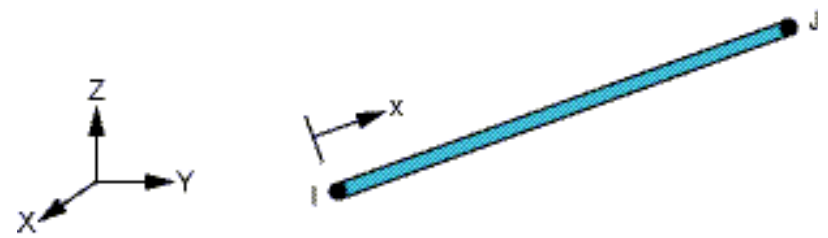

Figura 6. Elemento finito de treliça espacial LINK8 [11].

A estratégia de modelagem considera a influência da contribuição de painéis de alvenaria considerados como componentes estruturais, o que pode vir a influenciar diretamente no comportamento estrutural do edifício. Moreira [13] estudou a contribuição das alvenarias no que diz respeito ao enrijecimento global da estrutura, por meio de diagonais equivalentes, conforme ilustra a Figura 7.

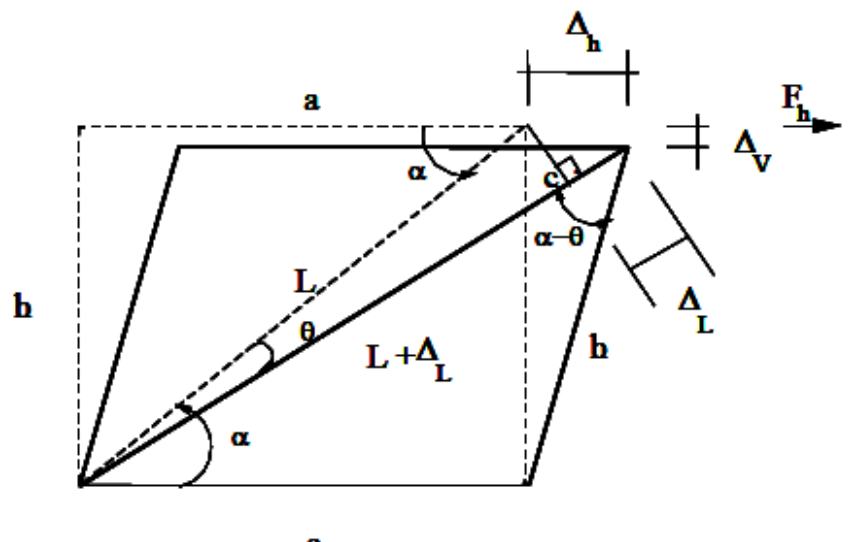

Figura 7: Painel elementar com uma diagonal [13]. 
Um modelo simplificado é utilizado para a determinação da rigidez cisalhante, $G$, no que diz respeito às diagonais representativas dos painéis de alvenaria, em função da geometria dos mesmos. Assim sendo, a área das diagonais equivalentes, representativa dos painéis de alvenaria do edifício, é expressa pela Equação (6) e a rigidez das diagonais é definida pela Equação (7).

$$
\begin{gathered}
A=\frac{k_{\text {diag }}}{E_{\text {aco }}} \frac{L}{\cos ^{2}\left(\alpha-\frac{\operatorname{sen} \alpha}{L+\cos \alpha}\right)} \\
k_{\text {diag }}=G \frac{a e}{h}
\end{gathered}
$$

Na Equação (7), as grandezas $a, e, h$ representam, respectivamente, a largura, espessura e a altura do painel de alvenaria, $G$ é o módulo de elasticidade transversal e $E_{a c ̧ o}$ é o módulo de elasticidade longitudinal do aço. Os valores do módulo de elasticidade transversal $G$ são obtidos de acordo com a Figura 8 [13].

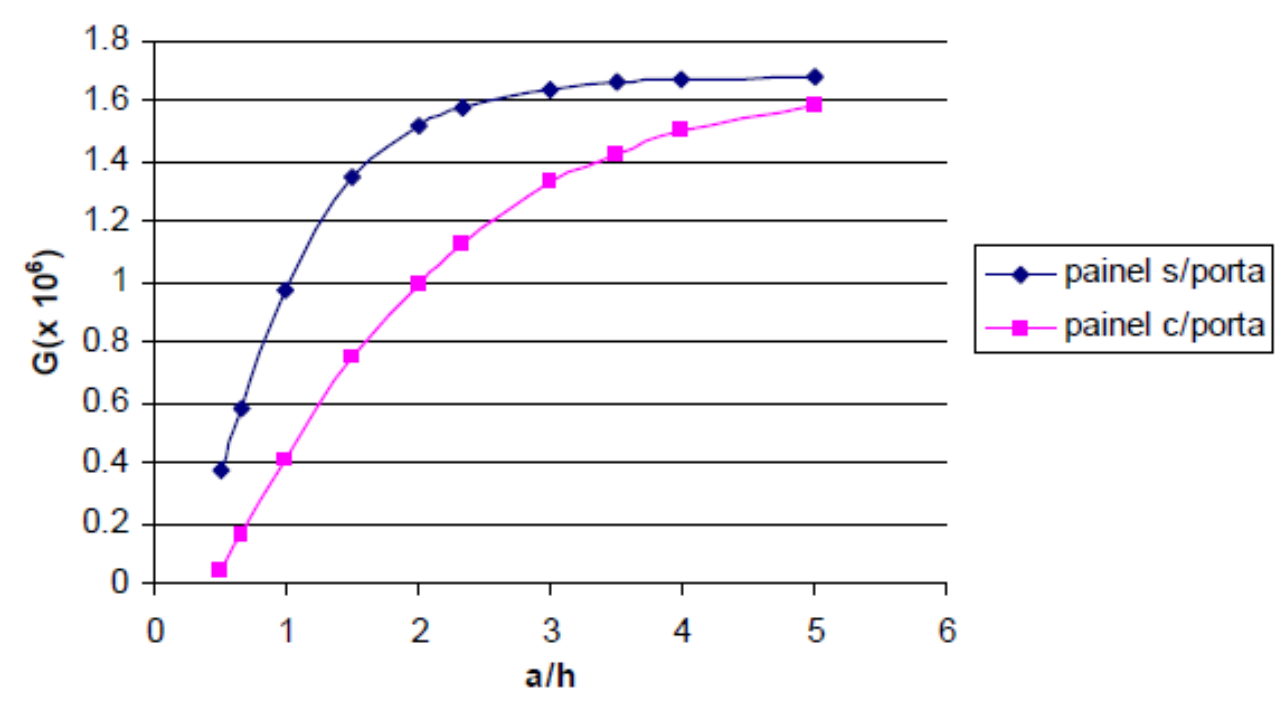

Figura 8. Curvas de Módulos de Elasticidade Transversal "G” [13].

\section{ANÁLISE DE AUTOVALORES E AUTOVETORES}

O problema clássico de autovalores (frequências naturais) e de autovetores (modos de vibração) é resolvido numericamente mediante o emprego do programa ANSYS [11]. A Tabela 2 ilustra os valores das quatro primeiras frequências naturais do edifício em estudo para duas situações distintas: sem a consideração do efeito dos painéis de alvenaria e com a consideração da influência dos painéis de alvenaria, simulados como componentes estruturais por meio de diagonais equivalentes. 
Verifica-se que a contribuição dos painéis de alvenaria aumenta os valores das frequências naturais do edifício, pelo menos duas vezes, indicando um acréscimo significativo nas características de rigidez da estrutura, Tabela 2. Cabe ressaltar que Chaker [14] utilizou dois modelos experimentais de edificações de três pavimentos, constituídos por pórticos típicos de concreto armado e, por meio de medições experimentais, em vibração livre, comprovou que o edifício aporticado com painéis de vedação em alvenaria de tijolos cerâmicos apresentou acentuado aumento na frequência fundamental da estrutura em relação ao modelo aporticado sem os painéis de alvenaria. Estes modelos, testados em laboratório, demonstraram que a rigidez lateral pode aumentar em até sete vezes no edifício com alvenarias em relação àquela sem a contribuição dos painéis de alvenaria (Chaker [14], apud Moreira [13]).

Tabela 2. Frequências fundamentais da estrutura em $\mathrm{Hz}$

\begin{tabular}{ccccc}
\hline \multirow{2}{*}{ Frequências } & \multicolumn{2}{c}{ Ansys [11] } & \multicolumn{2}{c}{ SAP2000 [15] } \\
& Sem alvenaria & Com alvenaria & Sem alvenaria & Com alvenaria \\
\hline $\mathrm{f}_{01}$ & 0,33 & 0,63 & 0,30 & 0,62 \\
$\mathrm{f}_{02}$ & 0,36 & 0,86 & 0,32 & 0,85 \\
$\mathrm{f}_{03}$ & 0,52 & 1,58 & 0.48 & 1,58 \\
$\mathrm{f}_{04}$ & 1,13 & 2,21 & 1.01 & 2,17 \\
\hline
\end{tabular}

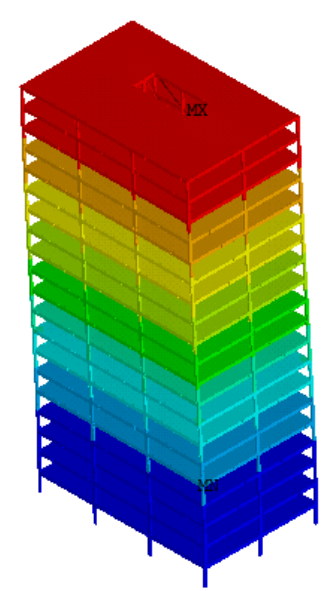

a) Primeiro modo de vibração $\left(f_{01}=0,33 \mathrm{~Hz}\right)$.

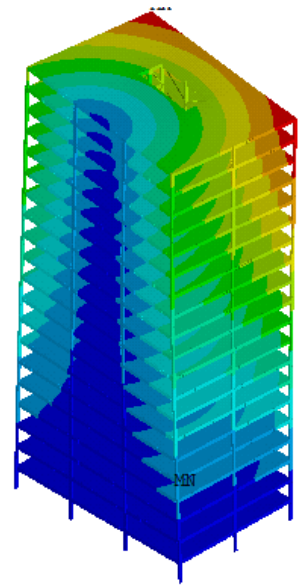

c) Terceiro modo de vibração $\left(\mathrm{f}_{03}=0,52 \mathrm{~Hz}\right)$.

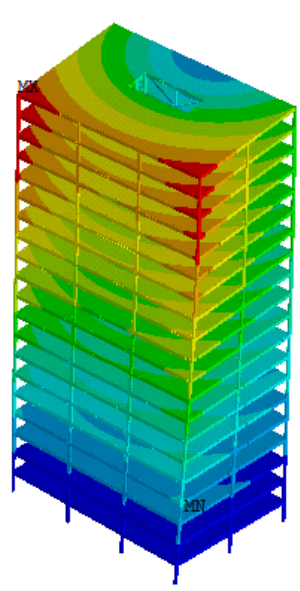

b) Segundo modo de vibração $\left(f_{02}=0,36 \mathrm{~Hz}\right)$.

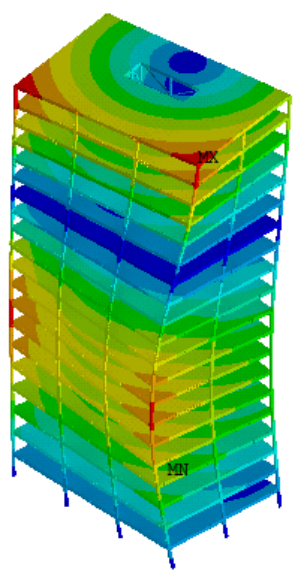

d) Quarto modo de vibração $\left(\mathrm{f}_{04}=1,13 \mathrm{~Hz}\right)$.

Figura 9. Modos de vibração da estrutura sem alvenaria [1]. 


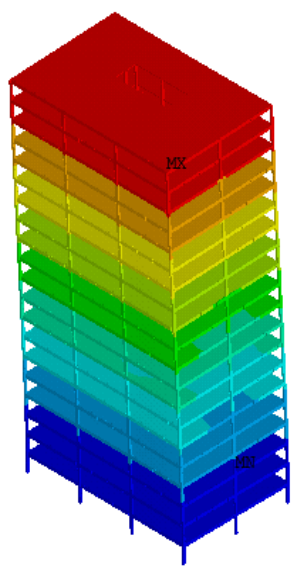

a) Primeiro modo de vibração $\left(\mathrm{F}_{01}=0,63 \mathrm{~Hz}\right)$.

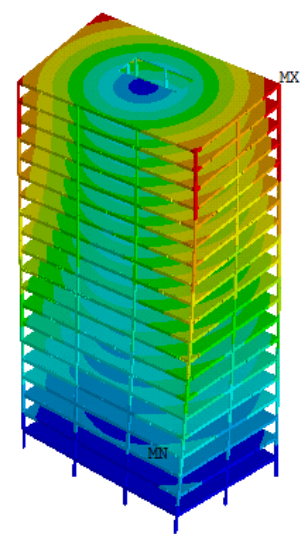

c) Terceiro modo de vibração $\left(\mathrm{F}_{03}=1,58 \mathrm{~Hz}\right)$.

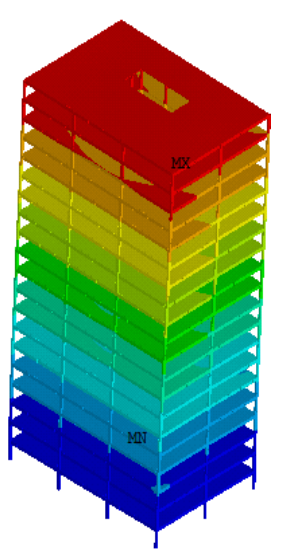

b) Segundo modo de vibração $\left(\mathrm{F}_{02}=0,86 \mathrm{~Hz}\right)$.

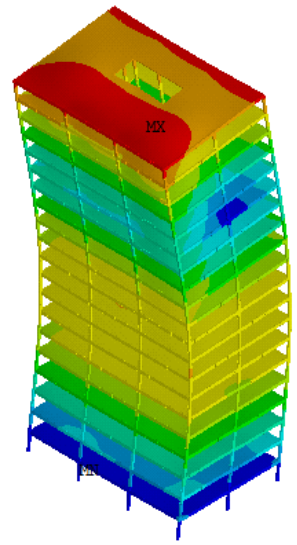

d) Quarto modo de vibração $\left(\mathrm{F}_{04}=2,21 \mathrm{~Hz}\right)$.

Figura 10. Modos de vibração da estrutura com alvenaria [1].

A Figura 9 apresenta os quatro primeiros modos de vibração da estrutura sem alvenaria. Observando a Figura 9, verifica-se a predominância dos efeitos de flexão para o primeiro modo de vibração em torno do eixo global horizontal $\mathrm{X}$. O segundo, terceiro e quarto modos de vibração apresentam predominância dos efeitos de torção em relação ao eixo vertical Y.

A Figura 10 apresenta os quatro primeiros modos de vibração da estrutura com alvenaria. Como mostrado na Figura 10, percebe-se que o primeiro e o segundo modos de vibração do edifício apresentam predominância dos efeitos de flexão em torno dos eixos globais horizontais $\mathrm{X}$ e Z, respectivamente. $\mathrm{O}$ terceiro modo de vibração apresenta característica predominante de torção em relação ao núcleo central do edifício, em torno do eixo global vertical Y. O quarto modo de vibração apresenta, novamente, predominância dos efeitos de flexão.

\section{ANÁLISE ESTÁTICA}

Uma análise estática foi realizada considerando-se a ação das cargas de vento atuantes na direção perpendicular em relação a maior dimensão da edificação. Tal análise foi feita utilizando-se o conceito básico de carregamento nodal equivalente, por meio do programa de elementos finitos ANSYS [11]. A Figura 11 ilustra a deformada do edifício (deslocamento lateral), quando submetido às cargas de vento. Este deslocamento lateral diz respeito aos efei- 
tos de flexão em torno do eixo global horizontal X. A Tabela 3 mostra valores dos deslocamentos translacionais horizontais estáticos obtidos em análises lineares e não lineares realizadas no programa de elementos finitos Ansys [11], além da diferença percentual entre esses valores. A Figura 12 ilustra o deslocamento lateral da edificação devido ao carregamento estático do vento.

Tabela 3. Deslocamentos translacionais horizontais estáticos [1]

\begin{tabular}{|c|c|c|c|}
\hline \multirow{2}{*}{ Pavimento } & \multicolumn{2}{|c|}{ Deslocamento horizontal $(\mathrm{cm})$} & \multirow{2}{*}{ Diferença } \\
\hline & Linear & Não linear & \\
\hline 0 & 0,00 & 0,00 & $0 \%$ \\
\hline 1 & 0.07 & 0.08 & $14 \%$ \\
\hline 2 & 0.23 & 0.24 & $4 \%$ \\
\hline 3 & 0.44 & 0.46 & $5 \%$ \\
\hline 4 & 0.70 & 0.72 & $3 \%$ \\
\hline 5 & 0.99 & 1.01 & $2 \%$ \\
\hline 6 & 1.31 & 1.34 & $2 \%$ \\
\hline 7 & 1.66 & 1.69 & $2 \%$ \\
\hline 8 & 2.03 & 2.07 & $2 \%$ \\
\hline 9 & 2.41 & 2.46 & $2 \%$ \\
\hline 10 & 2.81 & 2.86 & $2 \%$ \\
\hline 11 & 3.22 & 3.28 & $2 \%$ \\
\hline 12 & 3.65 & 3.71 & $2 \%$ \\
\hline 13 & 4.08 & 4.15 & $2 \%$ \\
\hline 14 & 4.51 & 4.59 & $2 \%$ \\
\hline 15 & 4.95 & 5.03 & $2 \%$ \\
\hline 16 & 5.39 & 5.48 & $2 \%$ \\
\hline 17 & 5.83 & 5.92 & $2 \%$ \\
\hline 18 & 6.26 & 6.36 & $2 \%$ \\
\hline 19 & 6.69 & 6.79 & $1 \%$ \\
\hline 20 & 7.12 & 7.23 & $2 \%$ \\
\hline
\end{tabular}

Observando-se os dados da Tabela 3 e as Figuras 11 e 12, verifica-se que a diferença média entre os deslocamentos considerando-se a análise estática linear e a análise estática não linear geométrica é da ordem de $3 \%$, o que mostra que a consideração da não linearidade geométrica pouco influenciou na resposta estática da estrutura investigada neste trabalho de pesquisa. 


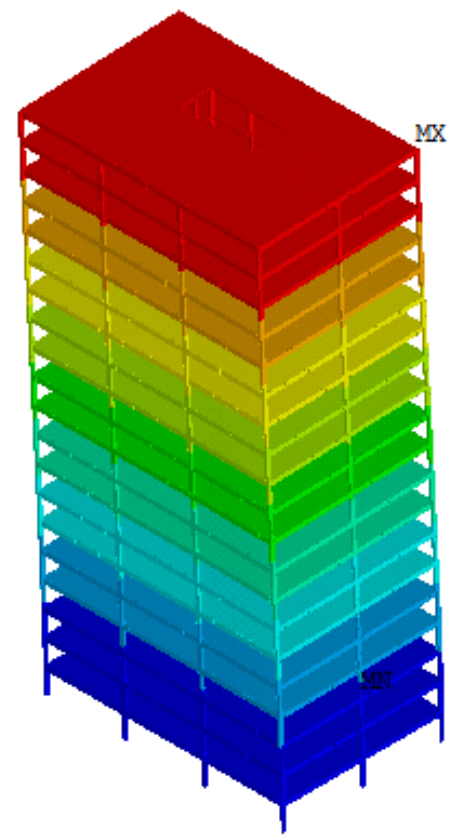

Figura 11. Deslocamento lateral do edifício quando submetido às cargas de vento [1].

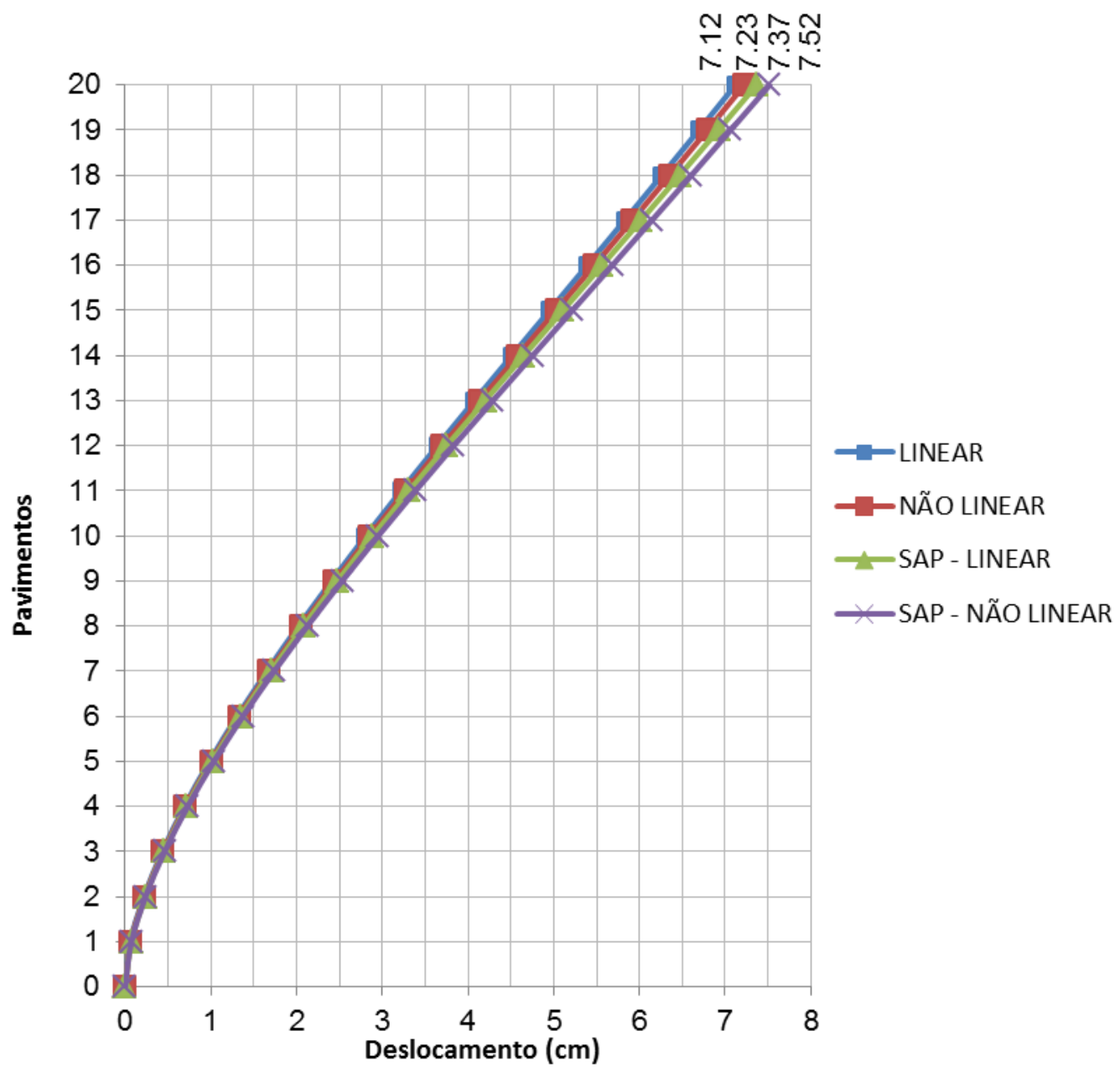

Figura 12. Deslocamentos translacionais horizontais estáticos [1]. 


\section{ANÁLISE DINÂMICA}

Nesta investigação, foram realizadas análises dinâmicas lineares e não lineares considerando-se às ações de vento modeladas, de forma simplificada, com base no emprego de funções harmônicas senoidais. A ação do vento foi considerada atuante na direção perpendicular em relação a maior dimensão da edificação.

O incremento de tempo utilizado para integração numérica das equações de movimento do sistema foi de $0,002 \mathrm{~s}\left(\Delta \mathrm{t}=2 \times 10^{-3} \mathrm{~s}\right)$. A contribuição dos painéis de alvenaria foi efetivamente considerada nas análises. $\mathrm{O}$ coeficiente de amortecimento estrutural adotado no presente trabalho é igual a $2 \%(\xi=2 \%)$, compatível com estruturas de aço e mistas.

Neste trabalho de pesquisa, a ação do vento é definida, de forma simplificada, como sendo uma função harmônica senoidal, mostrada na Equação (7), com duração de $35 \mathrm{~s}$, período do pulso igual ao período fundamental numérico da estrutura $T_{0}=1,60 \mathrm{~s}$ e o coeficiente de majoração $\mathrm{k}$ sendo adotado igual a $0,5,1,0$ e 2,0, respectivamente.

$$
F(t)=F_{0} \operatorname{sen}(k \omega t)
$$

Para a modelagem da ação dinâmica representativa da ação do vento sobre a estrutura foram adotados os seguintes dados de projeto [4]:

Velocidade básica do vento: $\mathrm{V}_{0}=35 \mathrm{~m} / \mathrm{s}$.

Fator topográfico: $\mathrm{S}_{1}=1,0$.

Categoria do terreno: $S_{2}=$ Categoria II, Classe B $(b=1,0$ e $p=0,15)$.

Fator estatístico: $\mathrm{S}_{3}=1,0$.

Altura do edifício: $\mathrm{h}=66 \mathrm{~m}$.

Dimensão perpendicular à linha de ação da força: $\mathrm{L}_{1}=30 \mathrm{~m}$.

Dimensão paralela à linha de ação da força: $\mathrm{L}_{2}=20 \mathrm{~m}$.

Razão de amortecimento crítico: $\zeta=0,01$.

Parâmetro da norma: $\gamma=1,2$.

Coeficiente de amplificação dinâmica: $\chi=1,30$.

Coeficiente de arrasto: $\mathrm{C}_{\mathrm{a}}=1,20$.

Deste modo, a pressão dinâmica do vento, Equação (2), pode ser determinada em qualquer ponto da face do edifício, ao longo da sua altura, segundo a Equação (9).

$$
q(z)=357,52\left[\left(\frac{z}{10}\right)^{0,30}+2,496\left(\frac{z}{66}\right)^{1,2}\right]
$$

O modelo matemático que descreve a rajada de vento aplicada no topo do edifício por meio de carga harmônica senoidal é ilustrado na Figura 13. A expressão final para o cálculo de $\mathrm{F}_{0}$ é apresentada na Equação (10).

$$
F(z)=12870,7\left[\left(\frac{z}{10}\right)^{0,30}+2,496\left(\frac{z}{66}\right)^{1,2}\right]
$$


Inicialmente, uma análise dinâmica linear foi realizada para se obter a variação ao longo do tempo do fator de amplificação dinâmico (FAD), associado aos deslocamentos translacionais horizontais correspondentes ao topo do edifício $(\mathrm{h}=66 \mathrm{~m})$ e na metade da altura da edificação $(\mathrm{h} / 2=33 \mathrm{~m})$. $\mathrm{O}$ fator de amplificação dinâmico (FAD) representa a relação entre os deslocamentos dinâmicos $\left(\mathrm{V}_{\mathrm{D}}\right)$, obtidos mediante a aplicação da ação do vento simulada através de função senoidal, exemplificada na Figura 13, normalizados com referência aos deslocamentos estáticos $\left(\mathrm{V}_{\mathrm{E}}\right)$, oriundos da aplicação das cargas estáticas de vento.

Posteriormente, uma análise dinâmica considerando-se a não linearidade geométrica da edificação foi realizada. As Figuras. 14, 15 e 16 apresentam a variação ao longo do tempo do fator de amplificação dinâmico (FAD) associado aos deslocamentos translacionais horizontais correspondentes ao topo do edifício $(\mathrm{h}=66 \mathrm{~m})$.

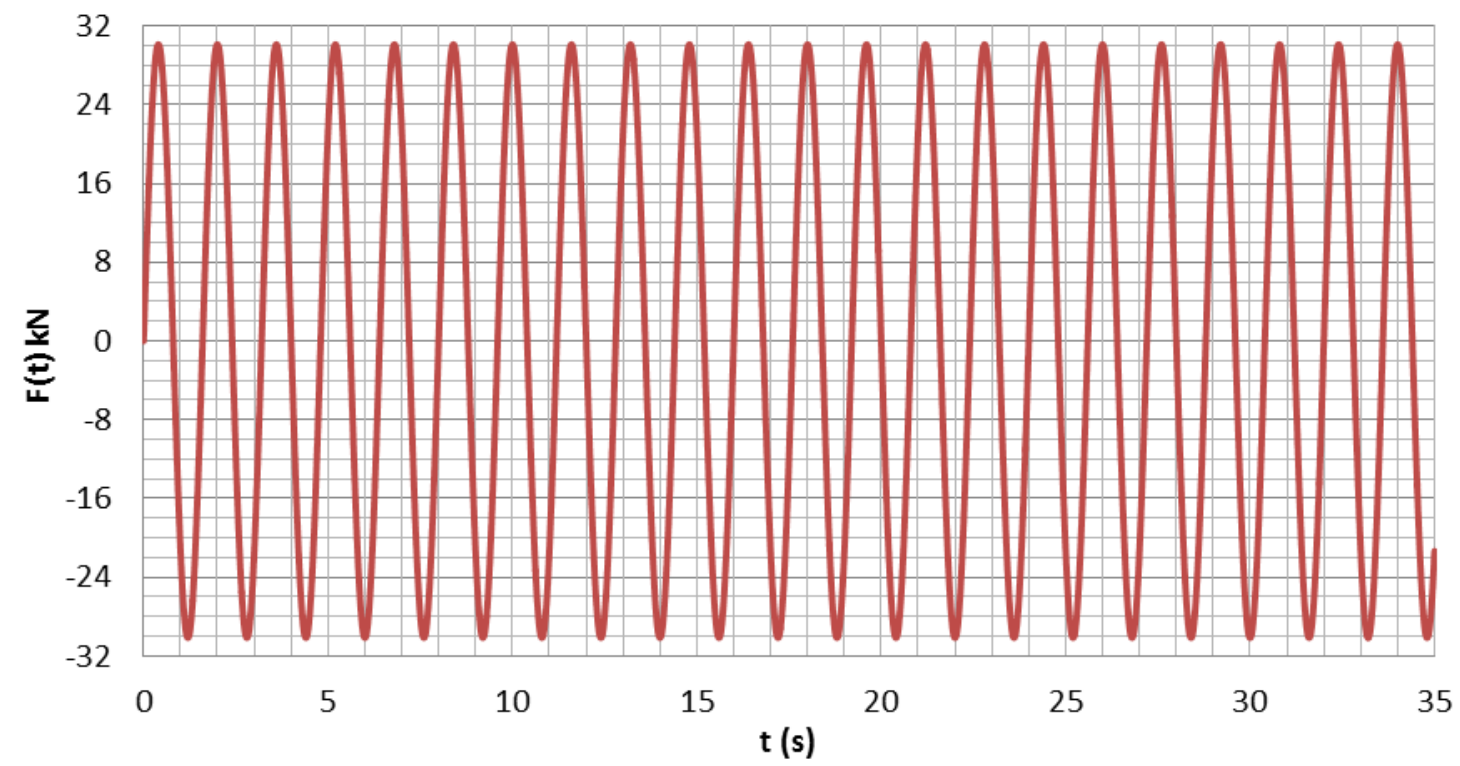

Figura 13. Força dinâmica devida à ação do vento aplicada no topo do edifício $(\mathrm{k}=1)$.

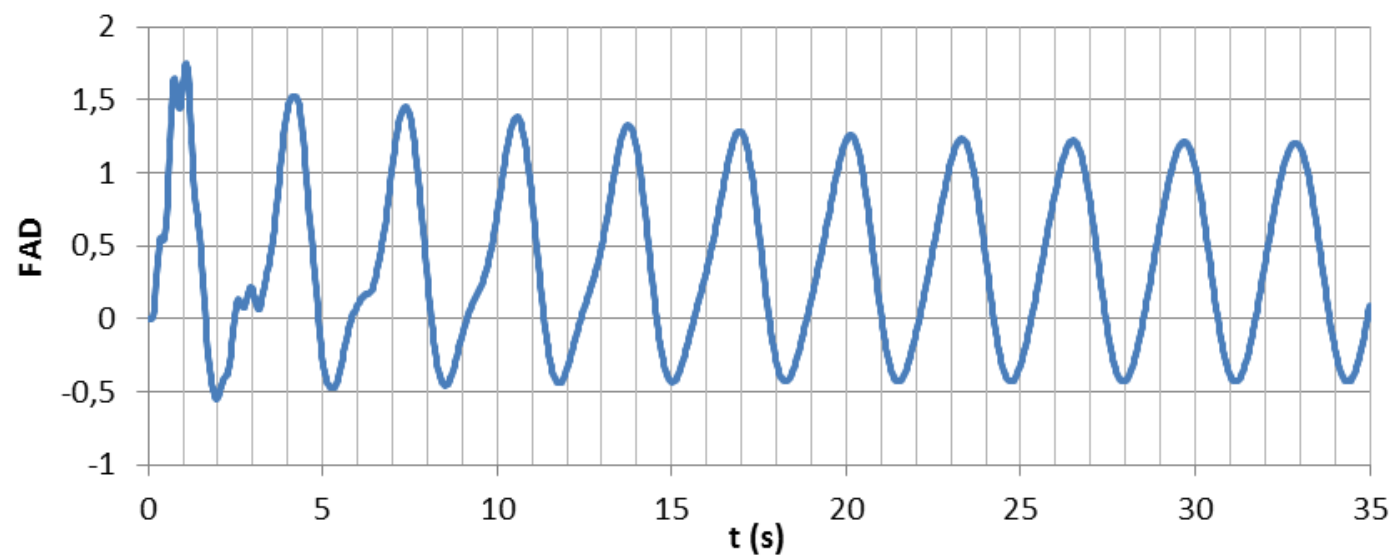

Figura 14. Fator de amplificação dinâmico não linear $\left(F A D=V_{D} / V_{E}\right)$, referente aos deslocamentos translacionais horizontais no topo do edifício $(\mathrm{h}=66 \mathrm{~m})(\mathrm{k}=0,5)[1]$.

A seguir, a Tabela 4 mostra os valores para os deslocamentos máximos da estrutura obtidos a partir de análises dinâmicas lineares e não lineares comparando-os aos obtidos em análises estáticas. 


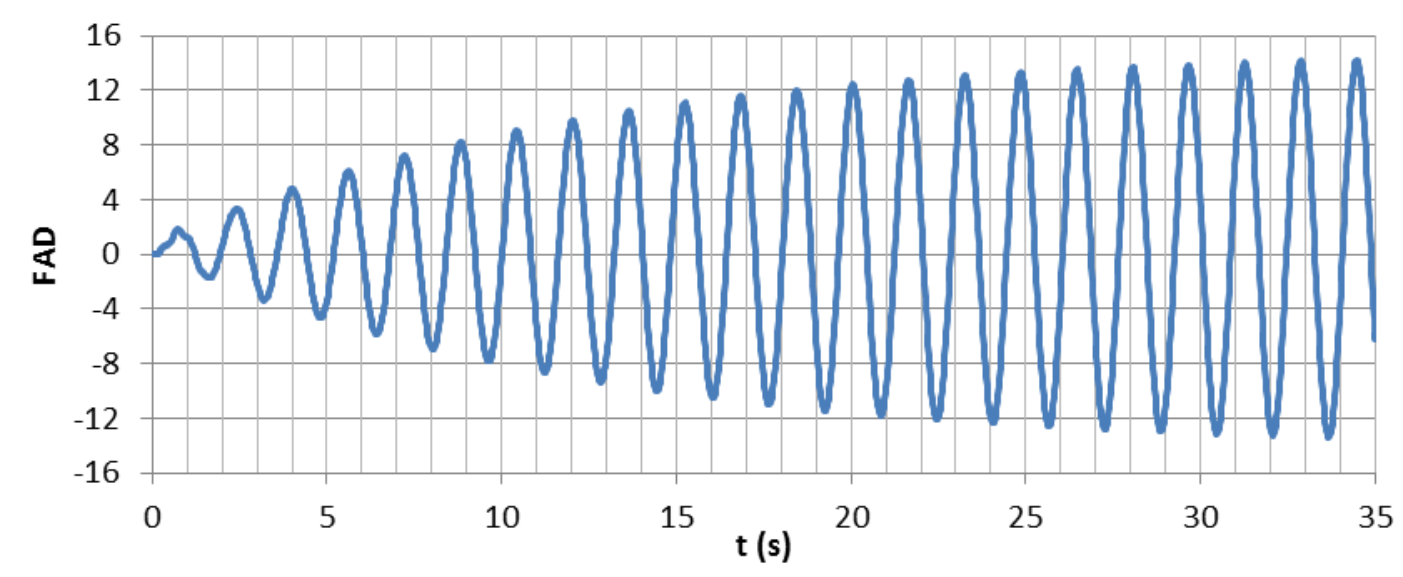

Figura 15. Fator de amplificação dinâmico não linear $\left(F A D=V_{D} / V_{E}\right)$, referente aos deslocamentos translacionais horizontais no topo do edifício $(\mathrm{h}=66 \mathrm{~m})(\mathrm{k}=1,0)[1]$.

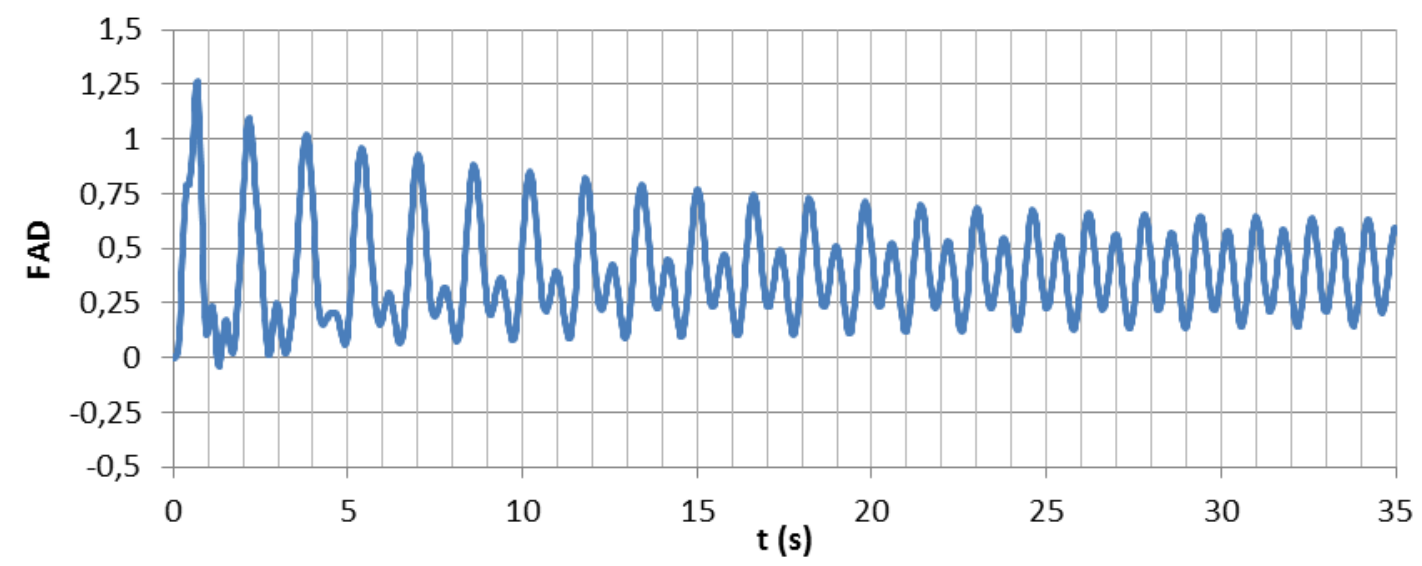

Figura 16. Fator de amplificação dinâmico não linear $\left(F A D=V_{D} / V_{E}\right)$, referente aos deslocamentos translacionais horizontais no topo do edifício $(\mathrm{h}=66 \mathrm{~m})(\mathrm{k}=2,0)[1]$.

Tabela 4. Deslocamentos translacionais horizontais máximos [1]

\begin{tabular}{cccccccc}
\hline \multirow{2}{*}{$\mathrm{k}$} & Altura & \multicolumn{3}{c}{ Linear } & \multicolumn{3}{c}{ Não Linear } \\
\cline { 3 - 7 } & & $\mathrm{V}_{\mathrm{E}}(\mathrm{cm})$ & $\mathrm{V}_{\mathrm{D}}(\mathrm{cm})$ & $\mathrm{FAD}_{\text {máx }}$ & $\mathrm{V}_{\mathrm{E}}(\mathrm{cm})$ & $\mathrm{V}_{\mathrm{D}}(\mathrm{cm})$ & $\mathrm{FAD}_{\text {máx }}$ \\
\hline \multirow{2}{*}{0,5} & $\mathrm{~h}$ & 7,12 & 12,54 & 1,76 & 7,23 & 12,65 & 1,75 \\
& $\mathrm{~h} / 2$ & 2,82 & 6,18 & 2,19 & 2,87 & 6,21 & 2,17 \\
\multirow{2}{*}{1,0} & $\mathrm{~h}$ & 7,12 & 105,31 & 14,79 & 7,23 & 102,97 & 14,24 \\
& $\mathrm{~h} / 2$ & 2,82 & 44,95 & 15,94 & 2,87 & 43,91 & 15,30 \\
\multirow{2}{*}{2,0} & $\mathrm{~h}$ & 7,12 & 9,19 & 1,29 & 7,23 & 9,11 & 1,26 \\
& $\mathrm{~h} / 2$ & 2,82 & 4,05 & 1,44 & 2,87 & 4,1 & 1,43 \\
\hline
\end{tabular}

Observando-se os resultados apresentados nas Figuras 14 e 16, verifica-se que os gráfícos associados à resposta dinâmica não linear geométrica do edifício apresentam duas fases distintas. Inicialmente, estes gráficos apresentam um trecho relativamente curto, da ordem de $5 \mathrm{~s}$, correspondente à fase transiente da resposta do sistema. Nesse trecho, em particular, alguns picos se apresentam um pouco mais elevados, mas percebe-se que esses picos têm o seu 
valor amortecido, ao longo do tempo, e a fase permanente da resposta dos modelos é rapidamente alcançada, onde se verifica, também, a influência do amortecimento estrutural sobre a resposta do sistema, Figuras 14 e 16.

O gráfico apresentado na Figura 15 corresponde a uma situação extrema de projeto, no que diz respeito à ressonância $(\mathrm{k}=1,0)$. Neste caso a frequência fundamental do edifício coincide com a frequência da excitação senoidal que simula a ação do vento, de forma simplificada. Evidentemente, nesta situação são esperadas amplificações dinâmicas muito elevadas e os valores máximos ocorrem na fase permanente da resposta do sistema, Figura 15.

Por outro lado, com base nos resultados apresentados na Tabela 4, verifica-se que os fatores de amplificação dinâmico máximos $\mathrm{FAD}_{\text {máx }}$ do edifício analisado variam de acordo com a frequência de excitação. Quando a excitação dinâmica é composta por frequências com valores inferiores às frequências da estrutura, o $\mathrm{FAD}_{\text {máx }}$ é da ordem de 1,7 (fase permanente da resposta). Considerando-se uma situação de ressonância este valor pode ser até 16 vezes superior aos efeitos estáticos. Finalmente, quando a carga dinâmica é composta por frequências superiores as frequências da edificação, estes valores se equivalem à resposta estática do edifício (fase permanente da resposta). Estas avaliações de ordem quantitativa devem ser consideradas, no que diz respeito a uma avaliação do projeto estrutural do edifício investigado, pois demonstram a importância da influência das ações dinâmicas sobre a resposta estrutural.

\section{CONSIDERAÇÕES FINAIS}

Este trabalho de pesquisa tem por objetivo o desenvolvimento de uma investigação para identificar e compreender o comportamento dinâmico de edifícios esbeltos em aço e mistos quando estes são submetidos à ação do vento. Para tal, a metodologia de análise considera o desenvolvimento de modelos numéricos tridimensionais apropriados, via método dos elementos finitos, com base na utilização do programa ANSYS [11].

Assim sendo, a resposta dinâmica de um edifício de vinte andares, composto por vigas e colunas de aço e lajes de concreto armado, formando um sistema estrutural misto com interação completa é investigada e os resultados são comparados com aqueles obtidos de acordo com a metodologia tradicional de projeto. A modelagem das rajadas de vento atuantes na estrutura do prédio foi simulada, de forma simplificada, por meio do emprego de cargas harmônicas senoidais.

No que diz respeito à análise das frequências naturais do edifício investigado foi verificado que a contribuição dos painéis de alvenaria aumenta os valores das frequências naturais do edifício, pelo menos duas vezes, indicando um acréscimo significativo nas características de rigidez lateral da estrutura. Esta contribuição para aumento da rigidez lateral da edificação contribui favoravelmente, no que diz respeito à resposta dinâmica da estrutura.

No que tange aos valores de amplificação dinâmica da resposta da estrutura analisada foi verificado que o fator de amplificação dinâmico máximo $\mathrm{FAD}_{\text {máx }}$ do edifício investigado varia de acordo com a frequência de excitação e pode atingir valores bem superiores à resposta estática, o que é bastante significativo. Tal fato é relevante, pois a depender do nível de amplificação dinâmica, este pode ser decisivo para o projeto estrutural do sistema. 


\section{Agradecimentos}

Os autores agradecem ao suporte financeiro fornecido pelas Agências de Fomento à Pesquisa do país, CAPES, CNPq e FAPERJ, que possibilitaram a realização deste trabalho de pesquisa.

\section{REFERÊNCIAS BIBLIOGRÁFICAS}

[1] Barboza, R.R. "Modelagem do comportamento dinâmico de edifícios esbeltos em aço e mistos (aço-concreto), submetidos à ação de cargas de vento". Dissertação de Mestrado. Programa de Pós-graduação em Engenharia Civil, PGECIV, Universidade do Estado do Rio de Janeiro, UERJ, Rio de Janeiro/RJ, Brasil, 2011.

[2] Barboza, R.R., J. G. S. da Silva, F. J. da C. P. Soeiro, E. da S. Goulart, L. R. O. de Lima. "Análise dinâmica de edifícios em aço e mistos submetidos à ação do vento". XXXII Iberian Latin American Congress on Computational Methods in Engineering, p. 1-16, Ouro Preto, Minas Gerais/MG, Brasil, 2011.

[3] Viana, A.C.P. e Araújo, T.D. "Análise dinâmica bidimensional de edifício submetido a rajadas de vento". XXX Iberian Latin American Congress on Computational Methods in Engineering, CD-ROM, 15 páginas, Armação de Búzios, Rio de Janeiro/RJ, Brasil, 2009.

[4] ABNT - Associação Brasileira de Normas Técnicas, "NBR 6123: Forças devidas ao vento em edificações". Rio de Janeiro/RJ, Brasil, 1990.

[5] Blessmann, J. "Introdução ao estudo das ações dinâmicas do vento". Editora da

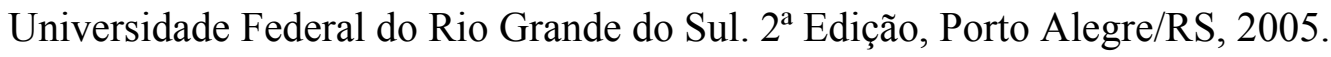

[6] Obata, S.H. "Vento sintético e a simulação de Monte Carlo - uma forma de considerar a característica aleatória e instável do carregamento dos ventos em estruturas". Exacta, 7 (1): 77-85, São Paulo/SP, 2009.

[7] Leite, W.C. "Análise dinâmica estocástica de estruturas de cabos de comportamento não linear sob vibrações aleatórias devidas ao vento". Tese de Doutorado. Escola Politécnica da Universidade de São Paulo, São Paulo/SP, 1998.

[8] Carril Junior, C. F. "Análise numérica e experimental do efeito dinâmico do vento em torres metálicas treliçadas para telecomunicações”. Tese de Doutorado. Escola Politécnica da Universidade de São Paulo, São Paulo/SP, 2000.

[9] Menin, R.C.G. “Análise estática e dinâmica de torres metálicas estaiadas”. Dissertação de Mestrado. Universidade de Brasília, Brasília/DF, 2002.

[10] Lazanha, E.C. "Análise dinâmica elastoplástica de estruturas metálicas sob excitação aleatória do vento". Dissertação de Mestrado. Escola Politécnica da Universidade de São Paulo, São Paulo/SP. 2003. 
[11] ANSYS. "Swanson Analysis Systems, Inc"., P.O. Box 65, Johnson Road, Houston, PA, 15342-0065, Version 10.0, Basic analysis procedures, Second edition, 2009.

[12] Assis, V.M. "Análise de edifícios de andares múltiplos com estrutura metálica". Dissertação de Mestrado. Escola de Engenharia. Universidade Federal de Minas Gerais, Belo Horizonte, Minas Gerais/MG, 2001.

[13] Moreira, T.V. "Análise da sensibilidade dinâmica de edifícios com estruturas esbeltas". Tese de Doutorado. Coordenação dos Programas de Pós-Graduação de Engenharia da Universidade Federal do Rio de Janeiro, Rio de Janeiro/RJ, 2002.

[14] Chaker, A.A., Cherifati, A. "Influence of masonry infill panels on the vibration and stiffness characteristics of R/C frame buildings", Earthquake Engineering Structural Dynamics, 28: 1061-1065, 1999.

[15] SAP2000. "Structural Analysis Program”. Computers and Structures, Inc., 2009. 